\title{
Evaluation of Decentration, Tilt and Angular Orientation of Toric Intraocular Lens
}

\section{Martin Fus (ID \\ Sarka Pitrova}

Faculty of Biomedical Engineering, Czech Technical University in Prague, Kladno, Czech Republic
Correspondence: Martin Fus

Tel +420725 713 921

Email martin.fus@cvut.cz
Purpose: The aim of this study was to develop software for the universal objective evaluation of factors influencing intraocular correction of astigmatism, such as decentration, tilt, axial position and angular orientation the toric intraocular lens (IOL).

Patients and Methods: Software was developed using the MS Visual Studio environment. The analysis was presented using images of 67 eyes with an implanted IOLs of the SN6ATx model series. Decentration and angular position of the lens were obtained from images of the anterior segment of the eye, using a Visucam unit. Tilt was measured on tomographic images from OCT Avanti (in meridian of highest tilt and perpendicular meridian) and preoperative biometry parameters of eye (axial length, anterior chamber depth - ACD, ocular lens thickness - LT, limbus diameter and mean keratometry value) including postoperative anterior chamber depth (pACD) were measured using Lenstar LS900.

Results: Applying the software methodology to the evaluation of individual toric IOL parameters, the following results were obtained: mean decentration $0.25 \pm 0.17 \mathrm{~mm}$ which was observed in $61.19 \%$ of eyes, mean misalignment to the planned axis equal to $3.8 \pm 3.6$ degrees, mean highest inclination equal to $3.7 \pm 1.2$ degrees and mean difference of pACD and $\mathrm{ACD}$ was equal to $1.46 \pm 0.31 \mathrm{~mm}$. There was only a weak nonsignificant correlation between preoperative ACD versus decentration and tilt of IOL or a weak significant correlation between preoperative LT and both decentration and misalignment of IOL.

Conclusion: The use of the presented methodology for determining the positional parameters of the toric IOL provided comparable results with the results of recent studies. Software design can be considered as a suitable alternative to previously published techniques, with the significant advantage of the possibility of using universal input images, their graphical editing and especially the possibility of comprehensive analysis of all parameters.

Keywords: astigmatism and cataract, toric IOL centration, toric IOL tilt, toric IOL axis misalignment

\section{Introduction}

Cataract is a curable disease only by surgical removal of the clouded lens and implantation of an artificial intraocular lens (IOL). This gives the surgeon a unique opportunity to correct the refractive ametropia of the eye for optimal postoperative visual acuity and the independence of the glasses at a given distance. However, approximately up to $40 \%$ of patients diagnosed with cataract also have corneal astigmatism at least $1 \mathrm{D}^{1-5}$ If such astigmatism is not corrected, the patient will not be able to achieve his or her best potential visual acuity without glasses, and will partially lose contrast sensitivity, especially in the dark. 
The most effective solution for astigmatism and cataract in one step is the implantation of a toric intraocular lens (TIOL). However, this presents the need to calculate the optical power of the IOLs, as well as the power of the correction cylinder value and the implant axis. Using modern non-suturing surgical techniques, optimised calculation formulas and virtual imaging systems, the surgeon is able to achieve the angular orientation of the TIOL in the correction axis with an accuracy of 1 degree.

Several studies have reported successful results in minimizing postoperative refractive astigmatism. Despite a slightly different approach to preoperative diagnosis and optimisation of calculations, a small percentage of eyes can be found in which the residual value of astigmatism exceeds a subjectively acceptable value up to $0.75 \mathrm{D}$ cylinder. One of the necessary steps in the search for the cause of these individual postoperative refractive surprises is the evaluation of the positional parameters of the lens position in the capsular bag (such as axis misalignment) and subsequent estimation of their influence on residual astigmatism. ${ }^{6-9}$ However, no conventionally used methodology or comprehensive tool is available to obtain and summarize these values to determine all positional factors simultaneously. Most research on TIOL positioning in the capsular bag is limited to developing a methodology for assessing one or two parameters, with the procedure adapted only to a specific device. Therefore, the aim of this research was to design a user-friendly tool to objectively assess all positional factors such as decentration, angular orientation, tilt, and axial position of the TIOL. The main requirement for the functionality of the custom software was the ability to universally use images acquired with commonly available visualization devices and to exploit this potential to create a free online tool. This study presents the design of the proposed tool for obtaining numerical outputs of each parameter. Using sample graphical outputs and then using the given methodology, a statistical evaluation on a set of patients is presented.

\section{Materials and Methods}

The design of a software tool for postoperative evaluation of positional parameters of the toric IOL was created, using the integrated development MS Visual Studio environment with the code language of the Visual Basic (.NET) editor. The user has access to tools for graphic editing of loaded images (adjusting contrast or brightness, cropping an image, creating a negative, etc.) and also to basic methods of image segmentation (image thresholding).

The first step is to log the user into the software and enter the patient's credentials, including biometry parameters of eye, choosing laterality and model or size of the optical part of IOL. Then the user has the option to choose to enter the individual sections and then upload a suitable image for analysis. Evaluating the centring of a toric IOL consists of two steps: finding the reference point and centre of the optical part of the IOL. The reference point can be selected by the user as the centre of the visual axis (for example as an approximation by the first Purkinje image), centre of pupil or limbus. After basic graphical editing (zooming in or out, etc.), the user is able to manually mark three points as the boundary of the selected reference point and then mark the optical part of the IOL. The boundaries are visualised by a triangle bounded by a circle (Figure 1, left). The result of the decentration is presented as a decentration vector (value and direction) due to the knowledge of the diameter of the optical part. Determining the angle orientation of the TIOL depends on the quality of the image by visualising the markers. The user is able to mark two opposite marking points determining the angular orientation of the toric IOL, and the output will be a graphically displayed orientation angle to the horizontal plane (Figure 1, right). The determined angular orientation of the TIOL was compared with the planned implant axis and evaluated as a misalignment in the following analysis.

The tilt of TIOL was evaluated on a similar principle as in the previous angle orientation procedure. For universality of input images, the user has the additional possibility of defining the reference plane. First option is choosing reference plane himself (for example, in OCT images of the anterior segment of the eye by marking the iris plane) or use default setting (reference plane is horizontal plane of image). For tilt analysis, is necessary to upload at least two scans - scan in the critical meridian (choosing the meridian with greatest inclination) and the perpendicular scan. An example of the measurement result is presented in Figure 2.

An additional parameter is the axial position of the IOL in the visual axis, which can be determined directly by measurement using optical biometry as a parameter of the postoperative depth of the anterior chamber (commonly called pACD). The user of the proposed software can use direct input of this value, or can use graphical measurement, as previously mentioned. It is necessary to use scans 


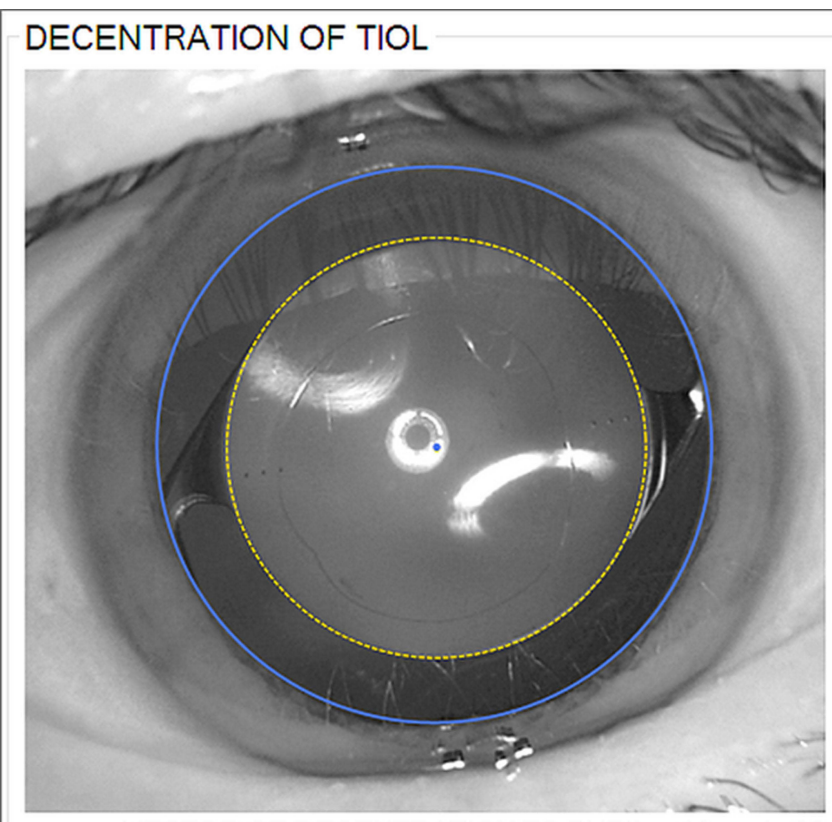

\section{ANGULAR ALIGNMENT OF TIOL}

VECTOR OF DECENTRATION TO PUPIL = 10 um in 90

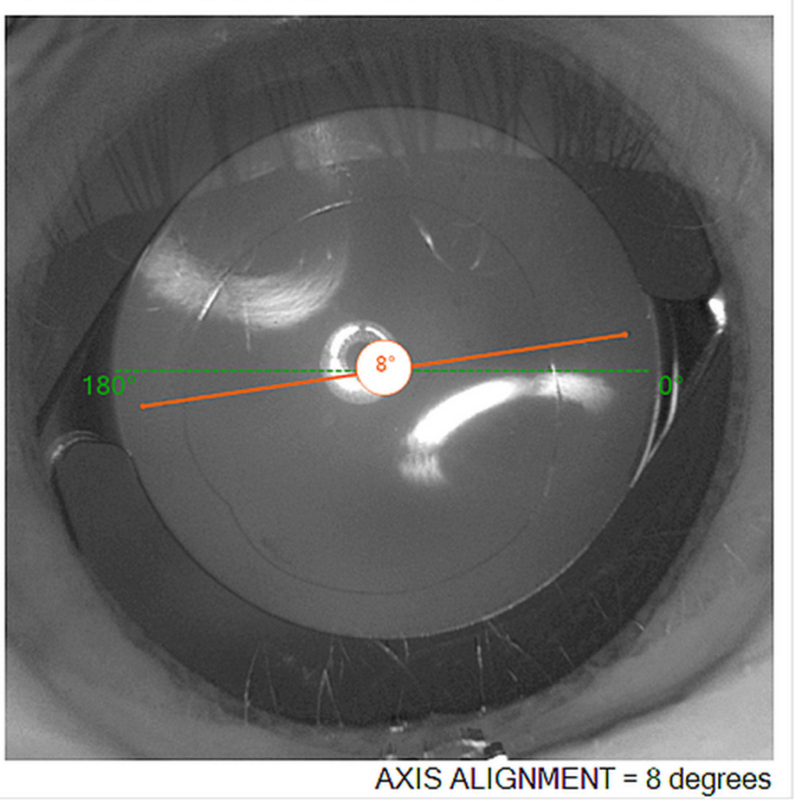

Figure I The resulting vector of decentration (left), the blue point is the centre of the pupil, which is highlighted by the blue circle, the yellow point is the centre of the optical part of the IOL, the edge of which is shown by the yellow circle. The decentration vector is determined by the relationship between these two points. The right part of the figure presents the determination of the angular orientation (orange line) of the toric IOL with respect to the horizontal plane (shown in green).

\section{TILT OF TIOL}

TILT IN CRITICAL PLANE

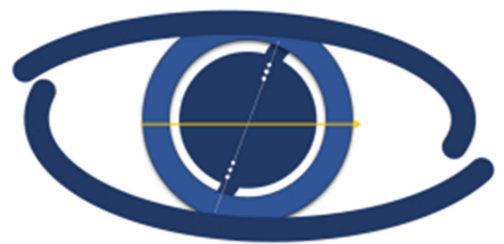

TILT IN PERPENDICULAR PLANE

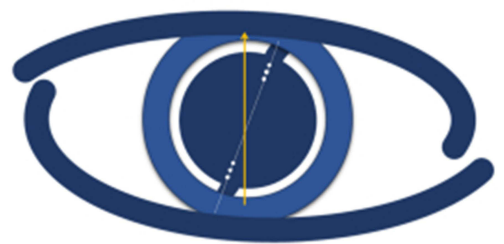

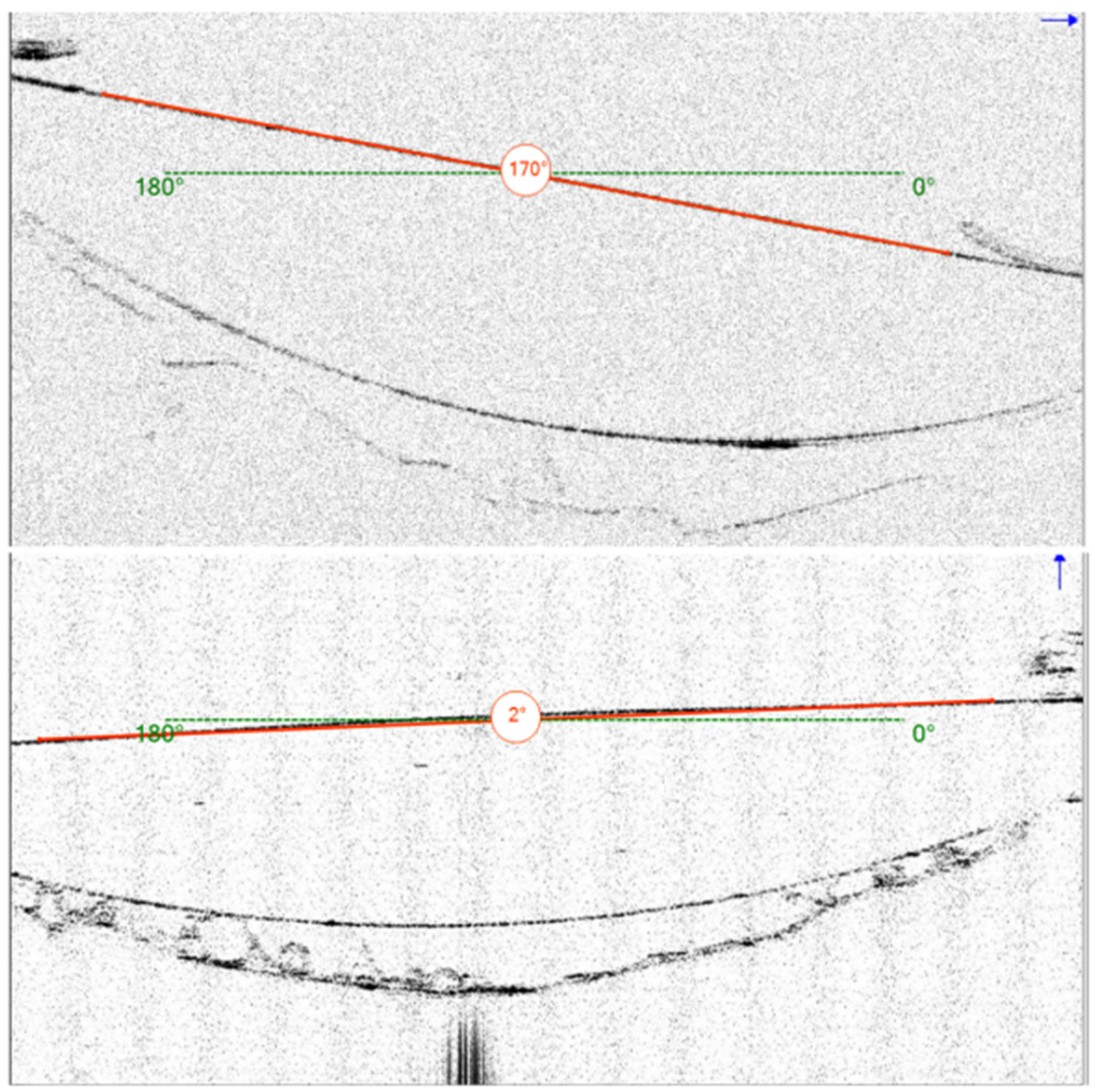

Figure 2 The resulting angle of tilt in critical and perpendicular meridians (tilt axis orange, reference plane green). In the upper part of the Figure, the resulting value of $170^{\circ}$ is not intentionally corrected, for the purpose of additional evaluation of the direction of tilt (nasal, temporal). 
of the whole anterior segments of the eye (to define the anterior surface of the cornea and the anterior surface of the IOL), but with the condition of knowing the dimensions of the scale of the image. After all measurements, the data are presented as a final report for printing, including graphical outputs of the analysed images.

Images of 67 eyes were used to present the resulting values of the TIOL positional parameters obtained with the custom software. The inclusion criteria were as follows: an arthephakic eye underwent cataract surgery with implantation of a toric intraocular lens into a capsular bag, image capturing was performed at least 2 weeks after surgery, operated by the same surgeon (Sarka Pitrova) and methodology, implanted toric IOL from the SN6ATx model line (calculated by Barrett Toric Calculator, using Verion image guided system for centration to pupil centre and axis alignment during surgery), eye without previous or postoperative disease or condition directly affecting graphically measured parameters, at least 14 days after surgery, optimal artificial mydriasis and suitable images for analyses.

The following data and captured images were used to demonstrate the principle of the tool. Images from Visucam 500 unit were used for decentration and angle orientation of toric IOL. The reference point for decentration was the centre of the pupil. OCT Avanti with anterior module was used for evaluation of IOL tilt in 8 different meridians of tomography images of IOL in the frontal plane (followed by choosing the critical and perpendicular meridians), due to the low depth of the scans, a horizontal plane, ie, a plane perpendicular to the fixation axis, was chosen as the reference plane. Lenstar LS900 was used to determine the biometry parameters of eye. such as axial length (AL), ocular lens thickness (LT), limbus diameter (WtW), mean keratometry value $(\mathrm{K})$ and especially preoperative (ACD) and postoperative anterior chamber depth (pACD), ie, the axial position of the IOL in the visual axis. So the value of pACD was entered manually.

Data obtained using custom software was used for file analysis. Decentration, tilt, axial position, and misalignment of the angular orientation of the TIOL relative to the planned position were evaluated using the maximum, minimum, median and mean values including standard deviation for patient group. The relationship between the IOL positional parameters and the biometry values of the eye was evaluated using Pearson's correlation coefficient.

\section{Results}

Custom software and the above methodology were used to determine the positional parameters of the TIOL. For this study, evaluation of IOL decentration to the centre of the pupil was selected. The mean scalar decentration (independently of the direction of the vector) was $0.25 \pm$ $0.17 \mathrm{~mm}$ (median $=0.21 \mathrm{~mm}$ ), and the mean vector of decentration was equal to $0.04 \mathrm{~mm}$ in 139 degrees. Decentration up to $0.50 \mathrm{~mm}$ was found in $89.55 \%$ eyes, and in $61.19 \%$ it was up to $0.25 \mathrm{~mm}$.

The mean misalignment of the intended and determined angular orientations of the toric IOL was $3.8 \pm$ 3.6 degrees, and the median was 3.0 degrees, respectively.

In our cases, with the OCT Avanti anterior segment module, it is only possible to display an intraocular lens at a shallow depth of field (but with 8 different meridians of radial scans in one measurement), so the horizontal plane perpendicular to the visual axis is set as the reference plane. The mean tilt value in the critical meridian (most tilted meridian) was observed at $3.7 \pm 1.2$ degrees (median $=3.5$ degrees), in the perpendicular direction 0.6 degrees (median $=0.5$ degrees). A maximum value of 10 degrees was recorded for a single case, the highest frequency (33.90\%) was set for a tilt of 4 degrees, but $91.5 \%$ of TIOL was tilted up to 5 degrees. The tilt in the nasal direction was defined for $96.6 \%$ of eyes, and in $64.4 \%$ of cases directly in a horizontal scan (180 degrees).

In the case of this study, only directly measured values using a Lenstar optical biometer were used. The mean pACD was equal to $4.6 \mathrm{~mm}$, and the mean difference value between anterior chamber depth before (ACD) and after surgery (pACD) was equal to $1.46 \mathrm{~mm}$.

The resulting values, including decentration, measured misalignment of intended correction axis, highest tilt (called critical), and difference between pre- and postoperative ACD and their correlation with the biometry parameters of the eye are presented in Table 1.

The finding of the correlations of all determined positional parameters of the toric intraocular lens was correlated with biometric values of the eye defined before surgery. There was only weak correlation between preoperative $\mathrm{ACD}$ versus decentration $(\mathrm{r}=0.23, \mathrm{P}>0.05)$ and inclination $(\mathrm{r}=0.23, \mathrm{P}>0.05)$ or weak correlation between LT and misalignment $(\mathrm{r}=0.28, \mathrm{P}<0.05)$ or weak negative correlation between LT and decentration $(\mathrm{r}=-0.31$, $\mathrm{P}<0.05)$. 
Table I Mean Values and Pearson's Correlation Coefficients $(r)$ of Determined Positional Parameters of Toric IOL

\begin{tabular}{|c|c|c|c|c|c|}
\hline \multicolumn{6}{|c|}{ A Total of 67 Toric IOLs } \\
\hline & \multirow[t]{2}{*}{ Decentration [mm] } & \multirow[t]{2}{*}{ Misalignment [Deg] } & \multicolumn{2}{|c|}{ Tilt [Deg] } & \multirow[t]{2}{*}{$\triangle \mathrm{ACD}[\mathrm{mm}]$} \\
\hline & & & Critical & Perpend. & \\
\hline Min & 0.01 & 0.0 & 1.0 & 0.0 & 0.47 \\
\hline Max & 0.68 & 17.0 & 10.0 & 2.0 & 2.26 \\
\hline Mean $\pm s d$ & $0.21 \pm 0.17$ & $3.8 \pm 3.6$ & $3.7 \pm 1.2$ & $0.6 \pm 0.5$ & $1.46 \pm 0.31$ \\
\hline Median & 0.21 & 3.0 & 3.5 & 0.5 & 1.44 \\
\hline $\mathrm{AL}$ & $r=0.10$ & $r=-0.01$ & \multicolumn{2}{|c|}{$r=-0.18$} & $r=-0.10$ \\
\hline ACD & $r=0.23$ & $r=-0.06$ & \multicolumn{2}{|c|}{$r=0.23$} & $r=-0.15$ \\
\hline LT & $r=-0.31$ & $r=\mathbf{0 . 2 8}$ & \multicolumn{2}{|c|}{$r=-0.11$} & $r=0.10$ \\
\hline WtW & $r=0.08$ & $r=0.04$ & \multicolumn{2}{|c|}{$r=0.11$} & $r=-0.03$ \\
\hline K & $r=-0.14$ & $r=0.06$ & \multicolumn{2}{|c|}{$r=-0.16$} & $r=-0.09$ \\
\hline
\end{tabular}

Note: $r=$ Pearson's correlation coefficient, significant values $(\mathrm{P}<0.05)$ are highlighted in bold.

Abbreviations: $\mathrm{AL}$, axial length; $\mathrm{ACD}$, preoperative anterior chamber depth; $\mathrm{LT}$, ocular lens thickness; WtW, limbus diameter; $\mathrm{K}$, mean keratometry; $\triangle \mathrm{ACD}$, difference of postoperative and preoperative ACD.

\section{Discussion}

The software design can be considered as an alternative to previously published techniques, with the significant advantage of the possibility of using universal input images, their graphical modification and especially the possibility of complex determination of all parameters.

For 67 eyes, mean values of decentration relative to the pupil centre $($ mean $=0.25 \pm 0.17 \mathrm{~mm})$, tilt $(3.7 \pm 1.2$ degrees), misalignment from intended axis orientation (3.8 \pm 3.6 degrees) and mean difference of postoperative and preoperative $\mathrm{ACD}$ (mean diff $=1.46 \pm 0.31 \mathrm{~mm}$ ) were determined. A significant weak negative correlation was found for preoperative LT and decentration, and a weak significant positive correlation for LT and misalignment. The other parameters did not reach a significant correlation.

There are several studies involving different approaches to the methodology and various models of IOL. Most of the research has acquired images for evaluation of decentralisation and tilt using Scheimpflug imaging systems $^{10,11}$ (SchIS) or the anterior segment $\mathrm{OCT}^{12,13}$ (ASOCT) imaging system, each with its own customised image processing software. Contact measurement methods, such as ultrasonic biomicroscopy ${ }^{14}$ inducing inaccuracies due to eyeball deformation or methods using Purkinje image reflections (from refractive interfaces) with their own software solution or using the Purkinje-meter, ${ }^{15,16}$ are not clinically widely used. The simplest method of evaluating intraocular lens decentration in ophthalmic practice can be determined using a slit-lamp by subjectively evaluating the distance between the edges of the optical part of the intraocular lens to the edges of the pupil in mydriasis. ${ }^{17,18}$ However, toric IOL alignment could also be determined, either subjectively by optical cut rotation ${ }^{19}$ or by image capture and subsequent analysis in graphics editors, ${ }^{20,21}$ or by the alternative use of aberrometry to separate corneal and lens-induced (respectively internal) astigmatism. ${ }^{22}$

The main factors influencing the change in positional parameters of the intraocular lens in the capsular bag are the size of the capsulotomy and the design of the intraocular lens or haptic. ${ }^{23}$ Experimental and optical simulations of aberrations caused by IOL decentration according to Lawu et $\mathrm{al}^{24}$ and Perez-Gracia et $\mathrm{al}^{25}$ or Ashena et $\mathrm{al}^{26}$ concluded that the critical value of decentration is the limit of about $0.50 \mathrm{~mm}$.

The resulting values of decentration and tilt of this study (mean dec $=0.21 \pm 0.17 \mathrm{~mm}$, mean tilt $=3.7 \pm 1.2$ degrees) were compared with the published results of other authors (independent of different IOL models and methods of measurement and selection of meridian of tilt): Assia et al: ${ }^{17} \mathrm{dec}<0.50 \mathrm{~mm}$ (125 eyes, slit-lamp, pupilar axis) tilt not evaluated; Baumeister et al: ${ }^{18}$ mean dec $=0.19 \pm$ $1.46 \mathrm{~mm}$ for spheric and $0.27 \pm 0.16 \mathrm{~mm}$ for aspheric IOL 
(21 eyes, slit-lamp, pupilar axis) and mean tilt $=2.89 \pm$ 1.46 degrees (spheric IOL) and $2.85 \pm 1.36$; Rosales et al: ${ }^{27}$ dec $=0.21 \mathrm{~mm}$ and tilt $=1.54$ degrees $(21$ eyes, SchIS $) ;$ de Castro et al: ${ }^{10} \mathrm{dec}=0.228 \mathrm{~mm}$ and tilt $=0.243$ (12 eyes, SchIS, pupilar axis); Wang et al: ${ }^{13} \mathrm{dec}=0.56 \pm 0.31 \mathrm{~mm}$ and tilt $=2.94 \pm 0.99$ degrees (39 eyes, AS-OCT, pupilar plane).

For misalignment comparison with the results of this study (mean deviation $=3.8 \pm 3.6$ degrees), the following results of alternative studies were chosen (regardless of the length of the postoperative period, only for SN6ATx models): Bauer et al: ${ }^{28}$ misal. $=3.50 \pm 1.90$ degrees $(53$ eyes, slit-lamp); Mendicute et al: ${ }^{29}$ misal. $=3.63 \pm 3.11$ degrees (30, slit-lamp); Mingo-Botin et al: ${ }^{30}$ misal. $3.65 \pm 2.96$ degrees (20 eyes, photo editor); Visser et al: ${ }^{31}$ misal. = $3.20 \pm 2.80$ degrees (67 eyes, slit-lamp); Grohlich et al: ${ }^{32}$ misal. $=4.92 \pm 4.10$ (41 eyes, not technique not specified); Zhu et al: ${ }^{33}$ misal. $=8.83 \pm 5.26$ degrees $(75$ eyes, photo editor).

\section{Conclusion}

Software and methodology for the objective evaluation of factors such as decentration, tilt, angular orientation (and possibly postoperative axial position) of the toric IOL affecting the correction of astigmatism have been successfully developed. The measured parameters generally correspond to the results of alternative methodologies. The software can be considered as a suitable alternative for the evaluation of the above-mentioned parameters in further studies, especially thanks to the possibility of graphical analysis using universal input images.

\section{Ethics Approval}

This work was performed in accordance with the Declaration of Helsinki and the internal Code of Ethics of the Czech Technical University in Prague. All participants gave informed consent to participate in this study, which was approved and approved by the internal ethics committee of the Ophthalmology Clinic JL, V Hůrkách 1296/10, 15800 Prague 5 - Nové Butovice, Czech Republic.

\section{Acknowledgments}

This work was supported by the Grant Agency of the Czech Technical University in Prague, grant No. SGS21/ 139/OHK4/2T/17

\section{Disclosure}

The authors report no conflicts of interest in this work.

\section{References}

1. Chen W, Zuo C, Chen C, et al. Prevalence of corneal astigmatism before cataract surgery in Chinese patients. J Cataract Refract Surg. 2013;39 (2):188-192. PMID: 23141077. doi:10.1016/j.jcrs.2012.08.060

2. Ferrer-Blasco T, Montés-Micó R, Peixoto-de-matos SC, GonzálezMéijome JM, Cerviño A. Prevalence of corneal astigmatism before cataract surgery. J Cataract Refract Surg. 2009;35(1):70-75. PMID: 19101427. doi:10.1016/j.jcrs.2008.09.027

3. Mohammadi M, Naderan M, Pahlevani R, Jahanrad A. Prevalence of corneal astigmatism before cataract surgery. Int Ophthalmol. 2016;36 (6):807-817. PMID: 26909501. doi:10.1007/s10792-016-0201-z

4. De Bernardo M, Zeppa L, Cennamo M, Iaccarino S, Zeppa L, Rosa N. Prevalence of corneal astigmatism before cataract surgery in Caucasian patients. Eur $J$ Ophthalmol. 2014;24(4):494-500. PMID: 24366768. doi:10.5301/ejo.5000415

5. Sharma A, Phulke S, Agrawal A, Kapoor I, Bansal RK. Prevalence of astigmatism in patients undergoing cataract surgery at a tertiary care centre in North India. Clin Ophthalmol. 2021;15:617-622. doi:10.2147/OPTH.S291467

6. Krall EM, Arlt EM, Hohensinn M, et al. Vector analysis of astigmatism correction after toric intraocular lens implantation. $J$ Cataract Refract Surg. 2015;41(4):790-799. PMID: 25840303. doi:10.1016/j. jcrs.2014.07.038

7. Kawahara A, Takayanagi Y. Vector analysis investigation of toric intraocular lens with no deviation from the intended axis. Clin Ophthalmol. 2016;10:2199-2203. PMID: 27843290; PMCID: PMC5098595. doi:10.2147/OPTH.S119755

8. Bachernegg A, Rückl T, Strohmaier C, Jell G, Grabner G, Dexl AK. Vector analysis, rotational stability, and visual outcome after implantation of a new aspheric toric IOL. J Refract Surg. 2015;31 (8):513-520. PMID: 26274517. doi:10.3928/1081597X-20150727-01

9. Nováček LV, Němcová $M$, Tyx $K$, et al. Evaluation of astigmatism-correcting efficiency and rotational stability after cataract surgery with a double-loop haptic toric intraocular lens: a 1-year follow-up. Biomed Hub. 2021;6(1):30-41. PMID: 33791315; PMCID: PMC7991491. doi:10.1159/000513894

10. de Castro A, Rosales P, Marcos S. Tilt and decentration of intraocular lenses in vivo from Purkinje and Scheimpflug imaging. Validation study. J Cataract Refract Surg. 2007;33(3):418-429. PMID: 17321392. doi:10.1016/j.jcrs.2006.10.054

11. Uzel MM, Ozates S, Koc M, Taslipinar uzel AG, Yılmazbaş $P$. Decentration and tilt of intraocular lens after posterior capsulotomy. Semin Ophthalmol. 2018;33(6):766-771. PMID: 29485320. doi:10.1080/08820538.2018.1443146

12. Li L, Wang K, Yan Y, Song X, Liu Z. Research on calculation of the IOL tilt and decentration based on surface fitting. Comput Math Methods Med. 2013;2013:572530. PMID: 23935701; PMCID: PMC3725812. doi:10.1155/2013/572530

13. Wang X, Dong J, Wang X, Wu Q. IOL tilt and decentration estimation from 3 dimensional reconstruction of OCT image. PLoS One. 2013;8(3):e59109. PMID: 23554982; PMCID: PMC3598664. doi:10.1371/journal.pone.0059109

14. Marianelli BF, Mendes TS, de Almeida Manzano RP, Garcia PN, Teixeira IC. Observational study of intraocular lens tilt in sutureless intrascleral fixation versus standard transscleral suture fixation determined by ultrasound biomicroscopy. Int J Retina Vitreous. 2019;5:33. PMID: 31384481; PMCID: PMC6664768. doi:10.1186/s40942-019-0182-y

15. Janunts E, Chashchina E, Seitz B, Schaeffel F, Langenbucher A. Reliability of a single light source Purkinjemeter in pseudophakic eyes. Optom Vis Sci. 2015;92(8):884-891. PMID: 26107022. doi:10.1097/OPX.0000000000000644 
16. Nishi Y, Hirnschall N, Crnej A, et al. Reproducibility of intraocular lens decentration and tilt measurement using a clinical Purkinje meter. J Cataract Refract Surg. 2010;36(9):1529-1535. PMID: 20692566. doi:10.1016/j.jcrs.2010.03.043

17. Assia EI, Wong JXH, Shochot Y. The effect on post-operative intraocular lens centration by manual intraoperative centration versus auto-centration. Clin Ophthalmol. 2020;14:3475-3480. PMID: 33122883; PMCID: PMC7591003. doi:10.2147/OPTH.S254152

18. Baumeister M, Bühren J, Kohnen T. Tilt and decentration of spherical and aspheric intraocular lenses: effect on higher-order aberrations. J Cataract Refract Surg. 2009;35(6):1006-1012. PMID: 19465285. doi:10.1016/j.jcrs.2009.01.023

19. George VE, George DS. Axis measurement strip for Haag-Streit BM900 series slitlamp. J Cataract Refract Surg. 2014;40 (10):1584-1587. PMID: 25263036. doi:10.1016/j.jcrs.2014.08.024

20. Shah GD, Praveen MR, Vasavada AR, et al. Software-based assessment of postoperative rotation of toric intraocular lens. J Cataract Refract Surg. 2009;35(3):413-418. PMID: 19251130. doi:10.1016/j. jcrs.2008.10.057

21. Becker KA, Auffarth GU, Völcker HE. Messmethode zur Bestimmung der Rotation und der Dezentrierung von Intraokularlinsen [Measurement method for the determination of rotation and decentration of intraocular lenses]. Ophthalmologe. 2004;101(6):600-603. German. PMID: 15197576. doi:10.1007/s00347-003-0951-7

22. Zhang Z, Li H, Zhou J, Zhang Y, Zhang S. Clinical evaluation of toric intraocular lens implantation based on iTrace wavefront keratometric astigmatism. BMC Ophthalmol. 2020;20(1):450. PMID: 33198718; PMCID: PMC7670723. doi:10.1186/s12886-020-01726-0

23. Ale JB. Intraocular lens tilt and decentration: a concern for contemporary IOL designs. Nepal J Ophthalmol. 2011;3(1):68-77. PMID: 21505548. doi:10.3126/nepjoph.v3i1.4281

24. Lawu T, Mukai K, Matsushima H, Senoo T. Effects of decentration and tilt on the optical performance of 6 aspheric intraocular lens designs in a model eye. J Cataract Refract Surg. 2019;45(5):662-668. Erratum in: J Cataract Refract Surg. 2019 May;45(5):708.PMID: 30876781. doi:10.1016/j.jcrs.2018.10.049

25. Pérez-Gracia J, Varea A, Ares J, Vallés JA, Remón L. Evaluation of the optical performance for aspheric intraocular lenses in relation with tilt and decentre errors. PLoS One. 2020;15(5):e0232546. PMID: 32365135; PMCID: PMC7197786. doi:10.1371/journal.pone.0232546
26. Ashena Z, Maqsood S, Ahmed SN, Nanavaty MA. Effect of intraocular lens tilt and decentration on visual acuity, dysphotopsia and wavefront aberrations. Vision (Basel). 2020;4(3):41. PMID: 32937 750; PMCID: PMC7559075. doi:10.3390/vision4030041

27. Rosales P, De Castro A, Jiménez-Alfaro I, Marcos S. Intraocular lens alignment from purkinje and Scheimpflug imaging. Clin Exp Optom. 2010;93(6):400-408. PMID: 20738324. doi:10.1111/j.1444-0938.20 10.00514.x

28. Bauer NJ, de Vries NE, Webers CA, Hendrikse F, Nuijts RM. Astigmatism management in cataract surgery with the AcrySof toric intraocular lens. J Cataract Refract Surg. 2008;34(9):1483-1488. PMID: 18721707. doi:10.1016/j.jcrs.2008.05.031

29. Mendicute J, Irigoyen C, Aramberri J, Ondarra A, Montés-Micó R. Foldable toric intraocular lens for astigmatism correction in cataract patients. J Cataract Refract Surg. 2008;34(4):601-607. PMID: 18361982. doi:10.1016/j.jcrs.2007.11.033

30. Mingo-Botín D, Muñoz-Negrete FJ, Won Kim HR, Morcillo-Laiz R, Rebolleda G, Oblanca N. Comparison of toric intraocular lenses and peripheral corneal relaxing incisions to treat astigmatism during cataract surgery. J Cataract Refract Surg. 2010;36(10):1700-1708. PMID: 20870116. doi:10.1016/j.jcrs.2010.04.043

31. Visser N, Ruíz-Mesa R, Pastor F, Bauer NJ, Nuijts RM, Montés-Micó R. Cataract surgery with toric intraocular lens implantation in patients with high corneal astigmatism. J Cataract Refract Surg. 2011;37(8):1403-1410. PMID: 21782086. doi:10.1016/j. jcrs.2011.03.034

32. Grohlich M, Miháltz K, Lasta M, Weingessel B, Vécsei-Marlovits V. Evaluierung der postoperativen Astigmatismuskorrektur und der postoperativen Rotationsstabilität zweier torischer Intraokularlinsen [Evaluation of Postoperative Astigmatism Correction and Postoperative Rotational Stability of Two Toric Intraocular Lenses]. Klin Monbl Augenheilkd. 2017;234(6):796-804. German. PMID: 28380650. doi:10.1055/s-0043-100656

33. Zhu X, He W, Zhang K, Lu Y. Factors influencing 1-year rotational stability of AcrySof Toric intraocular lenses. Br J Ophthalmol. 2016;100(2):263-268. PMID: 26089212. doi:10.1136/bjophthalmol2015-306656
Clinical Ophthalmology

\section{Publish your work in this journal}

Clinical Ophthalmology is an international, peer-reviewed journal covering all subspecialties within ophthalmology. Key topics include: Optometry; Visual science; Pharmacology and drug therapy in eye diseases; Basic Sciences; Primary and Secondary eye care; Patient Safety and Quality of Care Improvements. This journal is indexed on PubMed

\section{Dovepress}

Central and CAS, and is the official journal of The Society of Clinical Ophthalmology (SCO). The manuscript management system is completely online and includes a very quick and fair peer-review system, which is all easy to use. Visit http://www.dovepress.com/ testimonials.php to read real quotes from published authors. 